\title{
A prospective study of cytomegalovirus and herpes simplex virus disease in renal transplant recipients
}

\author{
DP WALKER, MAURICE LONGSON, NP MALLICK, ${ }^{*}$ RWG JOHNSON $†$
}

From the North Manchester Regional Virus Laboratory, the * Department of Renal Medicine and the University of Manchester † Department of Surgery, Manchester Royal Infirmary, Oxford Road, Manchester

SUMMARY A prospective study of 84 renal graft recipients demonstrated cytomegalovirus (CMV) disease after transplantation in $37 \%$ of patients. Reactivation infection was found in 20 of 44 patients $(46 \%)$ who were seropositive for CMV prior to transplant and primary CMV disease occurred in 11 of $40(28 \%)$ initially seronegative patients. Nearly all cases of primary disease $(91 \%)$ were associated with symptoms and in these cases CMV was probably acquired via the donated kidneys. Only $35 \%$ of the reactivation infections were associated with clinical symptoms. Actuarial life tables indicated that CMV disease did not reduce the length of graft survival. Herpes simplex virus (HSV) infections were diagnosed in $44(52 \%)$ of the patients and included a fatal case of disseminated disease associated with hepatitis.

It is widely recognised that an unwelcome result of the impaired immunological competence after renal transplantation is the increased susceptibility of renal transplant recipients to some viral infections. ${ }^{1-3}$ Herpesviruses, such as CMV, cause most episodes of overt viral disease after transplantation. ${ }^{2-5}$ The hosts' susceptibility to herpesvirus infection probably results from impairment of the cellular immune response. ${ }^{6}$ Although primary CMV infection may result in symptomatic disease, often severe and sometimes fatal, reactivation of endogenous virus usually results in less severe and often asymptomatic infection. $^{2}$ It remains unclear what effect CMV disease has on the length of graft survival or whether it can precipitate acute rejection episodes. This study attempted to determine the incidence of CMV and HSV disease after renal transplantation and, in particular, the effect of CMV on graft survival.

\section{Patients and methods}

Virus infections were monitored in 84 patients receiving renal transplant at Manchester Royal Infirmary between September 1979 and April 1981. Six patients had grafts from live related donors and the remainder received grafts from cadavers. All patients were given azathioprine and prednisolone?

Accepted for publication 11 May 1982 except for a small group (11 patients) admittedo towards the end of the study who received cyclosporin A (17 mg/kg body weight/day). Urine. saliva, and clotted blood samples were collected for viral studies from each patient at the time of transplant and fortnightly for three months. Thereafter, specimens were taken monthly for a further five months and whenever possible after that time. Serum was obtained from 40 of the renal donors. Additional specimens were collected at the discretion of the clinicians if the graft recipient developed symptoms suggestive of a viral illness. Specimens for virus culture were collected into transport medium containing $50 \%$ sorbitol and $0.4 \%$ bovine serum albumin in Hanks" buffered saline. All specimens were inoculated onto monolayers of human embryo fibroblasts established at NMRVL and of proven susceptibility to CMV, primary monkey kidney, HEp-2 cells and a continuous line of vervet monkey kidney (VERO) cells. Cell cultures were maintained for 3 to $4 \mathrm{wk}$ and viruses identified by their cytopathic effect followed by neutralisation, where appropriate. Donor and recipient sera taken before transplant were tested at a $1 / 4$ dilution for the presence of $\mathrm{CMV}$-specific antibody by an indirect fluorescent antibody method using FITC-conjugated antihuman whole serum (Wellcome Laboratories).

Thereafter recipients sera were routinely tested for antibodies to HSV and CMV by a microtitre complement fixation (CF) test starting at a serum 
dilution of $1 / 10$. Sera were tested for antibody to other viruses, such as adenovirus, influenza A and B and paramyxoviruses types 1,2 and 3 when patients showed symptoms of virus disease. All patients were tested every three months for the presence of hepatitis B virus surface antigen by a passive haemagglutination test (Hepatest, Wellcome Laboratories).

Viral infections were diagnosed by isolation of virus and/or a fourfold or greater rise in CF antibody. Actuarial life tables for graft survival were plotted as described by Peto et al. ${ }^{8}$

\section{Results}

Evidence of CMV disease was found in 31 of the 84 patients $(37 \%)$ after renal transplant. Prior to transplant CMV-specific antibody was found in 44 of the 84 patients $(52 \%)$ using the immunofluorescence test. Primary CMV infections were diagnosed in 11 of the $40(28 \%)$ patients who were initially seronegative for CMV and reinfections or reactivation infection identified in 20 of the $44(46 \%)$ patients who were seropositive before transplant (Table 1). The majority of CMV infections were diagnosed between 30 and 90 days after transplant, somewhat later than the bulk of HSV infections (Table 2). The earliest and latest CMV episodes occurred 11 and 165 days after transplant respectively and the mean time to diagnosis of primary and secondary infections was identical in both cases ( 54 days).

The most common clinical effects of primary CMV disease, in the absence of other acute complications, were raised temperature, leucopenia and thrombocytopenia (Table 3). Primary CMV disease was nearly always symptomatic $(91 \%)$ and clinically more severe than reactivation infection $(35 \%$ symptomatic) which, when overt, was limited to slightly raised temperatures and leucopenia. Primary disease was associated in five cases with signs of respiratory infection which varied from a mild cough with no radiological evidence of pneumonia (in four cases) to severe pneumonitis (one fatal case). CMV was isolated from the nasopharynx in all five patients, three patients seroconverted to CMV, but the antibody response in the fatal case was minimal. Other observed abnormalities included hepatosplenomegaly, atypical mononuclear cells and abnormal liver function tests. The results indicated that the graft may be the means of transmission of CMV to susceptible (CMV-seronegative) recipients (Table 4).

The CMV antibody status of the renal donor was known in 21 of the 40 recipients who were seronegative before transplant. The six seronegative patients who received kidneys from seronegative
Table 1 Primary and secondary cytomegalovirus (CMV) disease in renal transplant recipients

\begin{tabular}{lll}
\hline $\begin{array}{l}\text { *CMV antibody status } \\
\text { before transplant }\end{array}$ & $C M V$ disease & $\begin{array}{l}\text { \% of group } \\
\text { with CMV disease }\end{array}$ \\
\hline Positive 44 & 20 (secondary) & 46 \\
Negative 40 & 11 (primary) & 28 \\
\hline
\end{tabular}

*Determined by an indirect immunofluorescent antibody test.

Table 2 Occurrence of cytomegalovirus (CMV) and herpes simplex virus $(H S V)$ disease in renal transplant recipients

\begin{tabular}{lccll}
\hline \multicolumn{5}{c}{$\begin{array}{l}\text { Viral episodes after transplantation } \\
\text { Days after transplant }\end{array}$} \\
\cline { 2 - 5 } & $0-29$ & $30-59$ & $60-89$ & 90 \\
\hline CMV & 6 & 15 & 7 & 3 \\
HSV & 34 & 9 & 1 & 0 \\
\hline
\end{tabular}

Table 3 Clinical symptoms associated with primary and secondary cytomegalovirus (CMV) disease in renal transplant recipients

\begin{tabular}{llll}
\hline No of patients & \multicolumn{3}{l}{ Symptoms } \\
\cline { 2 - 4 } & $\begin{array}{l}\text { Leucopenia } \\
<500 \text { WBC } \times 10^{\circ} / 1\end{array}$ & $\begin{array}{l}\text { Fever } \\
>37.55^{\circ} \mathrm{C}\end{array}$ & $\begin{array}{l}\text { Thrombocytopenia } \\
<100 \times 10^{\circ} / 1\end{array}$ \\
\hline Primary CMV 11 & $9(82 \%)$ & $8(73 \%)$ & $\begin{array}{l}4(36 \%) \\
\text { Secondary CMV 20 } 7(35 \%)\end{array}$ \\
\hline
\end{tabular}

Table 4 Cytomegalovirus (CMV) disease in relation to the $C M V$ antibody status of the renal donor and recipient

\begin{tabular}{llcl}
\hline $\begin{array}{l}{ }^{*} \text { CMV antibody } \\
\text { status of recipient }\end{array}$ & ${ }^{*}$ CMV antibody & No of & No of patients \\
status of donor patients & with CMV disease \\
\hline- & - & 6 & $0(0 \%)$ \\
- & + & 15 & $6(40 \%)$ \\
+ & - & 4 & $2(50 \%)$ \\
+ & + & 16 & $7(44 \%)$ \\
\hline
\end{tabular}

${ }^{*}$ Determined prior to renal transplant using an indirect immunofluorescent antibody test.

donors remained free of CMV disease whereas 6 of 15 $(40 \%)$ seronegative patients who had kidneys from seropositive donors developed infection. The CMV antibody status of the renal donor did not appear to influence the development of CMV disease in patients who were seropositive before transplant.

The overall appearance of life tables for patients with CMV disease and those without the infection were similar (Figure) and their actuarial graft survival values at one year were $68 \%$ and $63 \%$ respectively (value for all grafts was $65 \%$ ). The life tables for patients with or without CMV disease were compared using the logrank test. ${ }^{8}$ The $X^{2}$ value obtained showed 


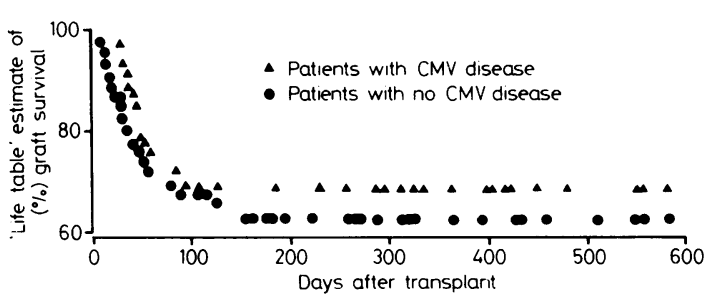

Life table estimates of graft survival in renal transplant recipients with, or without, cytomegalovirus (CMV) disease.

no significant difference between the two groups ( $X^{2}$ $=0.326$ ). The mean number of rejection episodes per patient in the first 90 days after transplant was similar with or without CMV disease ( 1.3 per patient, CMV group; $1 \cdot()$ per patient, non-CMV group) and there appeared to be no association between episodes of acute rejection and CMV disease.

Evidence of HSV infection was found in $44(52 \%)$ patients after transplant. Virus was cultured from the oropharynx in all cases and 13 patients $(30 \%)$ showed a fourfold or greater rise in CF antibody. Excretion of HSV was detected earlier than CMV, most patients $(77 \%)$ shedding virus within the first 30 days and all by 90 days (Table 2). Eleven patients developed oral HSV lesions, three of these having orofacial lesions. In two cases the lesions persisted for several weeks.

The only other viral episodes detected were three cases of adenovirus disease and a case of varicellazoster, none of which was related to acute rejection episodes. The adenoviruses were associated with cases of upper respiratory infection and the courses of these illnesses were unremarkable. There were no cases of serum hepatitis in any of the patients throughout the course of the investigation. Nine patients died during the course of the investigation and virus infections undoubtedly contributed to two of these fatalities. A 37-year-old woman developed disseminated HSV infection with hepatitis and died on the 23rd day after transplant. ${ }^{9}$ A 56-year-old man developed CMV pneumonitis and died 47 days after transplant. CMV was isolated from saliva, bronchial aspirate, and spleen and CMV inclusion bodies were seen in lung tissue obtained at necropsy.

The above patients were given the antiviral drug adenine arabinoside (vidarabine) with little effect. A further patient who had pyrexia and was excreting HSV improved rapidly after treatment with vidarabine, but a causal relation cannot be claimed. Idoxuridine $(30$ or $40 \%$ ) in dimethyl sulphoxide was used successfully on several occasions to ameliorate the effects of orofacial herpes simplex.

\section{Discussion}

Thirty-five per cent of all the patients had CMV infections following transplant and of those who were initially seropositive $46 \%$ had evidence of CMV disease. This figure is lower than that reported by some workers for reactivation infections $(91 \%$, Betts et al $;^{10} 97 \%$, Chatterjee et al ${ }^{1}$ but somewhat nearer to that recorded by Warrell et $a l^{2}(62 \%)$. There is no obvious explanation why we detected such a low rate of reactivation infections as the incidence of primary CMV disease in our seronegative patients $(28 \%)$ was not far removed from that $(35 \%)$ reported by Warrell et al. " It is possible that the "low dose" steroid regimen used in our study permitted fewer reactivation infections than have been observed in patients undergoing more aggressive chemotherapy.

The results obtained in this study support previous observations that CMV can be transmitted with the graft as none of our seronegative patients given kidneys from seronegative donors developed infection, whilst $40 \%$ of seronegative patients receiving kidneys from seropositive donors acquired CMV disease.

Blood transfusions given to seronegative patients were not tested for CMV antibody before use indicating that in our study there was no evidence of CMV being transmitted in stored blood. Howevero the number of patients involved was small (6) and the possibility of the transmission of CMV to seronegative patients by this route merits further investigation. The overall incidence of primary CMV disease in our patients $(13 \%)$ was similar to that reported by Warrell et $a^{2}(13.8 \%)$ and as in their study almost all patients with primary infection were symptomatic. In comparison, only $35 \%$ of our patients with secondary $\mathrm{CMV}$ disease were symptomatic. Most CMV disease was encountered in the second month after transplant and unlike other authors, we did not find that primary infection occurred earlier after transplant than reactivation disease. However, the number of our patients with primary disease was small (11) and this result may be unreliable.

Graft survival was apparently not affected by CMV disease and indeed was marginally better in patients with the infection. Although there was a slightly increased incidence of rejection episodes in patients with CMV infection, there was no correlation in time. However, CMV infection and primary disease in particular was responsible for individual episodes of morbidity and mortality. Opinion is divided on whether or not CMV disease is associated with episodes of rejection. Several studies have failed to demonstrate a relation. ${ }^{212-15}$ This view is contradicted 
by other authors. ${ }^{1016-20}$ Further careful studies of large groups of patients are obviously required.

The incidence of HSV infection in our patients $(52 \%)$ was similar to that reported in previous studies $\left(47 \%\right.$, Warrell et al $;^{2} 54 \%$, Korsager et al $\left.{ }^{21}\right)$. As in this previous work the most common clinical manifestations of HSV disease were oro-facial lesions although a fatal case of disseminated HSV with hepatitis was documented. ${ }^{9}$ There was a surprisingly low incidence of varicella-zoster and other viral infections in our patients. It is possible that some episodes of acute viral illness were "missed" during the later stages ( $>3$ months) of the follow-up if they occurred between visits to the renal clinic.

The use of the immunosuppresant cyclosporin A after renal transplantation is becoming more widespread and as yet there is little information on virus infections in patients on this regimen. The small number of patients in this study given cyclosporin $\mathrm{A}$ does not allow a valid comparison of virus infections in this group compared with patients taking steroids but work on this aspect is continuing and will be reported at a later date.

\section{References}

' Ho M. Virus infections after transplantation in man. Arch Virol 1977;5:1-24.

2 Warrell MJ, Chinn I, Morris PJ, Tobin JO'H. The effects of viral infections on renal transplants and their recipients. $Q J \mathrm{Med}$ 1980;194:219-31.

${ }^{3}$ May AG, Betts RF. Freeman RB, Andrus CH. An analysis of cytomegalovirus infection and HLA antigen matching on the outcome of renal transplantation. Ann Surg 1978;187:110-7.

+ Betts RF. Freeman RB, Douglas RG et al. Transmission of cytomegalovirus infection with renal allograft. Kidney Int 1975;8:387-94.

s Ho M, Suwansirikul S, Dowling JN, Youngblood LA, Armstrong JA. The transplanted kidney as a source of cytomegalovirus infection. N Engl J Med 1975;293:1109-12.

- Linnemann CC, Kaufmann CA, First MR, Schiff GM, Phair JP. Cellular immune response to cytomegalovirus infection after renal transplantation. Infect Immun 1978;22:176-80.

' Johnson RWG, Mallick NP, Gooi TH, Cohen GL, Orr WMcN. Improved patient and graft survival after cadaveric renal transplantation. Br J Surg 1977;64:831.
${ }^{*}$ Peto R, Pike MC. Armitage P. et al. Design and analysis of randomized clinical trials requiring prolonged observation of each patient. Br J Cancer 1977:35:1-39.

" Walker DP. Longson M. Lawler W. Mallick NP. Davies JS. Johnson RWG. Disseminated herpes simplex virus infection with hepatitis in an adult renal transplant recipient. J (lin Pathol 1981;34:1041-6.

'" Betts RF, Freeman RB, Douglas RG, Talley TE. Clinical manifestations of renal allograft derived primary cytomegalovirus infection. Am J Dis Child 1977;131:759-63.

" Chatterjee SN, Fiala M. Weiner J. Stewart JA. Stacey B. Warner N. Primary cytomegalovirus and opportunistic infections. JAMA 1978:240:2446-9.

12 Armstrong JA. Evans AS. Rao N. Ho M. Viral infections in renal transplant recipients. Infect Immun 1976:14:970-5.

${ }^{13}$ Suwansirikul S, Rao N. Dowling JN, Ho M. Primary and secondary cytomegalovirus infection: clinical manifestations after renal transplantation. Arch Intern Med 1977:137:1026-9.

${ }^{14}$ Descamps P. Bedrossian J, Nochy D et al. Renal transplantation and viral infections. 111. Clinical and virological correlations. Biomedicine 1978:28:113-9.

is Pass RF. Long WK. Whitley Rj. Soong SJ. Diethelm AG. Reynolds DW, Alford CA. Productive infection with cytomegalovirus and herpes simplex virus in renal transplant recipients: role of source of kidney. J Infect Dis 1978:137:55662.

${ }^{16}$ Light JA. Burke DS. Association of cytomegalovirus (CMV) infections with increased recipient mortality following transplantation. Transplant Proc 1979;11:79-82.

" Naraqi S, Jonasson O. Jackson GG. Yamashiro HM. Clinical manifestations of infections with herpesviruses after kidney transplantation. Ann Surg 1978;188:234-9.

${ }^{1 x}$ Fryd DS, Peterson PK, Ferguson RM, Simmons RL. Balfour HH. Najarian JS. Cytomegalovirus as a risk factor in renal transplantation. Transplantation 1980;30:436-9.

${ }^{19}$ Cappel R. Hestermans O. Toussaint et al. Cytomegalovirus infection and graft survival in renal transplant recipients. Arch Virol 1978;56: 149-56.

20 Lopez C. Simmons RL. Mauer SM. Najarian JS, Good RA. Association of renal allograft rejection with virus infections. Am J Med 1974;56:280-9.

${ }^{21}$ Korsager B, Spencer ES, Mordhorst C-H. Andersen HK. Herpesvirus hominis infections in renal transplant recipients. Scand J Infect Dis 1975;7:11-9.

Requests for reprints to: Dr DP Walker, 61 Fenshurst Gardens, Long Ashton, Bristol, England. 